\title{
Narrating Railways through accounts and films
}

\section{Chitresh Shrivastva}

\author{
2MAIS, Christ University, Bangalore, India
}

\begin{abstract}
Indian Railways, now more than 160 years old has not only played the role of the lifeline of the nation, but has also been instrumental in diminishing boundaries and as seen not only in documentaries, but railways have been effectively been employed in movies as well as an instrument of reunion of the two lovers, or the start of a new relationship (Azmi: 2007). While many debates range around the benefits to railways, many accounts of people working for the railways have through the means of narrations as seen in the story loyalty by Jim Corbett or during the most traumatic of the political events such as partition, yet again railways have been personified as people who come to narrate stories or during the British Raj they have been used as means to describe the experiences of the people travelling in different classes (Kerr: 2007) or by writers like Bharatendu Harischandra or by our very own nationalist leaders like Mahatma Gandhi and Jawaharlal Nehru who travelled across the country in the first, second and third classes and observing wide differences amongst the people of different classes. The paper seeks to examine the role played by the writers and nationalists during the colonial era and modern era and how the portrayal of Railways have altered over a span of 160 years from an object of criticism to an object of fantasy
\end{abstract}

Keywords-Partition, accounts, nationalists, experiences.

\section{INTRODUCTION}

Indian Railways is one of the largest railway network in the world with $1,15,000 \mathrm{kms}$ of track across 8000 stations with 21000 trains running daily with the number of people travelling by the railways almost equaling to the population of Australia and employing 14 lakh people almost equal to army emerges as the lifeline of the nation. While we regard railways as a colonial instrument which resulted in the drain of financial sources and as remarked by Romesh Chandra Dutta as a wasteful expenditure (Misra: 2009) and used by the British to spread its tentacles across the subcontinent in terms of administrative efficiency, Indian Railways has been interpreted as means beyond just economics. Indian Railways has been portrayed in stories of partition as trains of death which carried dead bodies across the border as portrayed in Bollywood or books like train to Pakistan by Khushwant Singh or portraying different emotions witnessed in human nature such as that of jealousy (Chopra: 1988) , reunion (Ali: 2007) or love (Chopra: 2005) to mention a few. Many poems and writings also have reflected a variety of reactions by nationalists and writers on the impact that the railways has in terms of space and the religious connection of the railways when we look at Bharatendu Harischandra. In the following sections we will look at the representation of Railways in:
a) Literature
b) Films

\section{REVIEW OF LITERATURE}

Indian Railways has often been represented in literatures which describes the pleasures of a train journey across different journey and the diverse culture and nature of people that we come across during a journey spanning of 2.5 days to even 4 days has been very well portrayed in Around the world in 80 trains by Monisha Rajesh (2012).The task of constructing the railways was plagued by various challenges which is seen in the accounts of Ian.J.Kerr in his book Engines of Change (Kerr: 2012), which again is talked off in the short story Loyalty by Jim Corbett, where he talks about his experience as a fuel inspector who travelled in the forests as trains that time ran on wood or billets other than coal.In his account Peter Morey (2000) the role of railways during the partition of India in Khushwant Singh's novel, Train to Pakistan (1956) Regarded as the "Third World literature", the novel explains the impact of village by the passing of a train through the fictitious village of Mano Majra, the time of the day with the first. The description of the village in connection to the village also draws religious connections by mentioning a village mullah and a Sikh priest therefore bringing in a notion of interdependence between the village and the train and therefore the village of Mano Majra is described as an idealized and a trans historical location, which will soon emerge as the new frontier of the soon to be partitioned Punjab.

Yet our social understanding of the railways is shaped through the Monsoon Railways (2004) which talks about 
the social initiatives taken by the railway employees such as the poor children whose lives as portrayed in the documentary makes one ponder on the holistic domains of our lives and introspect if we are actually moving forward or are we still static when we talk about development, thus we don't only limit to the railways, but to the lives of the people who are dependent on the railways for their livelihood.

MS Dhoni - The Untold Story (2016) again is a brilliant example which effectively employs train as a symbol of opportunity knocking at you and conveying a message of seizing the opportunity is upto the person or else you would wait have to wait for the next opportunity. The train and the opening of the door have been effectively employed as a symbolic shot.

\section{RAILWAYS IN LITERATURE}

Indian Railways has often been represented in literatures which describes the pleasures of a train journey across different journey and the diverse culture and nature of people that we come across during a journey spanning of 2.5 days to even 4 days has been very well portrayed in Around the world in 80 trains by Monisha Rajesh (2009). The author does not weave a story within the train itself, but also drives the attention of the readers towards the places she goes through the trains and the uniqueness in each journey which ranges from visiting to places of religious significance to places which make one introspect oneself, the variations in the train journey through the entire book proves the point that railways is an inevitable link in the modern Indian Context which is divided by states, but united by railways.

The task of constructing the railways was plagued by various challenges which is seen in the accounts of Ian.J.Kerr in his book engines of change, which again is talked off in the short story Loyalty by Jim Corbett where he talks about his experience as a fuel inspector who travelled in the forests as trains that time ran on wood or billets other than coal. The author talks about his responsibility of transporting the fuel. Through the story we are not only exposed to the hazards of the forest dwelling, but also the ability to reach to the remotest corners of the country. The construction of Hill Railways to the remotest hill regions is an excellent example.

Railways came under tremendous resistance during the period of colonial rule. Gandhiji in his book Hind Swaraj has criticized the coming up of railways and has described it as a necessary evil and considered it as the reason behind the poverty. In his account Peter Morey (2000) the role of railways during the partition of India in Khushwant Singh's novel, Train to Pakistan (1956) Regarded as the "Third World literature", the novel explains the impact of village by the passing of a train through the fictious village of Mano Majra, the time of the day with the first. The description of the village in connection to the village also draws religious connections by mentioning a village mullah and a Sikh priest therefore bringing in a notion of interdependence between the village and the train and therefore the village of Mano Majra is described as an idealized and a trans historical location, which will soon emerge as the new frontier of the soon to be partitioned Punjab. The following is an extract which shows the regulation of the life in Mano Majra by the train.

"By the time the 10:30 morning passenger train from Delhi comes in, life in Mano Majra has settled down to its dull daily routine. Men are in fields. Women are busy with their daily chores. Children are out grazing cattle by the river. Persian wheels squeak and groan as bullocks go round and round...., Sparrows fly about the roofs, trailing straw in their beaks. Pye-dogs seek the shade of the long mud walls. Bats settle their arguments, fold their wings, and suspend themselves in sleep"

The railways also helped in understanding the discrimination by the British. Nationalist leaders like Jawaharlal Nehru, Mahatma Gandhi and C. Rajagopalachari travelled in the third class where people travelled in the most troubled conditions in the third class coaches which was availed by passengers who belonged to the lower classes and were deprived of the luxurious ambience that were otherwise enjoyed by the people of the first class. Literary sources also point towards existence of Princely State Railways which were managed individually by the kingdoms (Misra: 2009), thus we find the legacy of luxurious trains which resemble the trains of the princely states thereby can be regarded as being one of the most expensive trains which target the higher classes of the Indian segment and the Foreign Tourists. Taking people across the region and exposing the travellers to the past legends. What is even more evident that the railways has been a populist measure ever since its advent and of the late has been attempted to have reduced the influence of populism on the Railways (Menon \& Mahajan) The Railways had been the target of the nationalist leaders and the revolutionaries, especially when we look at the Quit India Movement. One of the major events in the Indian independence struggle. On the eve of Quit India Movement a passenger train was stopped at Kakori Station near 
Lucknow by armed revolutionaries who included Ram Prasad Bismil, Chandrasekhar Azad, Sachindranath Sanyal, Jogesh Chandra Chatterjee and Manmath Nath Gupta and the government money was looted.

Or for that example when we look at modern day narrations of railway journeys such as in Chai Chai (Ghosh: 2009) which takes us to stations which we encounter while travelling from one point to another, stations which disappear in the race to reach your destination, but when you risk out from the conventional journeys to exploring the unexplored is something that makes Bishwanath Ghosh's account different from other accounts, making us realise the importance of small towns in the journey of railways. In the next session, I shall try to elaborate on the role of the railways in the visual media and its impact

\section{RAILWAYS IN FILMS}

Indian Railways have had a role not only in terms of oral and written presentation, but with the help of visual media, railways have received a widespread recognition in both good and bad ways depending on the circumstance. In this paper I intend to discuss only from the positive aspect, Railways have had from the beginning been a means of portrayal of India and its significance. Through railways there have been different shades of emotions that have been portrayed, romance being one of them, when we look at the song sequence of meri sapno ki rani from Aradhana (1969) or Parineeta (2005) or for that matter Dilwale Dulhaniya Le Jayenge (1995) where we witness the reunion of two lovers at a railway station. The Darjeeling toy train is very special not only from the perspective of being one of the oldest hill railways, but also being one of the special attractions from the Bollywood point of view or when we look at certain advertisements like the Honda. Other hill railways like the Udagamandalam Toy train have been spotted in Dil Se, especially Chhaiyan Chhaiyan song which has been shot on the very same railway.

Feelings of jealousy, revenge, diversity and unity have been again portrayed in a beautiful manner in The Burning Train (1988) where jealousy takes over and results in change of relations between friends (Danny and Vinod Khanna) where we find an attempt to destroy the train named Super Express and the train being a reason for the breakup of a married life and reunion of a friend. Many themes have been witnessed in the movie.

The diversity of people travelling in the train has also been shown by the presence of a priest and a Muslim clerk, a Pathan and a Punjabi and a Christian. The last scene makes the diversity very evident with people praying to god for returning home alive in different ways. It would rather be tragic to limit ourselves only to Bollywood.We should also focus on the portrayal of railways by different documentaries, which I shall be discussing further. The first example is The Great Indian Railway (Hunt: 2002) which symbolizes railways as an instrument of power and prestige and the nostalgia over the loss of rich heritage which is marked by the demise of the steam locomotives shown in the documentary. The string of diverse connections naturally and individually has been portrayed in the documentary through the exhibition of contrasts such as the deserts of Rajasthan and the greenery to of countryside. Or the chaotic scenes of big junctions like Chennai to silence of stations like the Palur Station that is no longer operational. The trains of common man to the trains of the rich. To the trains that talk about the glory of the ruling families like the Scindias. Let us not forget that the luxury air-conditioned intercity trains such as the Shatabdi were introduced by Late. Madhav Rao Scindia who was instrumental in the bringing of the train in 1988. Yet our social understanding of the railways is shaped through the Monsoon Railways (2004) which talks about the social initiatives taken by the railway employees such as the poor children whose lives as portrayed in the documentary makes one ponder on the holistic domains of our lives and introspect if we are actually moving forward or are we still static when we talk about development, thus we don't only limit to the railways, but to the lives of the people who are dependent on the railways for their livelihood.

Despite India being unified and partitioned simultaneously, the railways responsibility of keeping the relations between countries intact through cross border train services to Bangladesh and Pakistan (Although due to tense relations with Pakistan has led to irregularity of train services)this service has again been showed in Gadar - EkPrem Katha (2002)and we happened to have train services to Sri Lanka, once upon a time, which after the cyclone of 1964 (Bhandari: 2005) ceased to exist and are now looking towards having a rail link to Russia, which would be boost to the cultural exchange between the two countries.

Chennai Express (2013) is yet again another important movie which shows the "diversity" that our railways exhibits which is more regional in nature. The examples mentioned above are more to do with the Bollywood melodrama which aims at understanding the role of trains in uniting and breaking of relations or reunion of lost relations. MS Dhoni - The Untold Story (2016) again is a brilliant example which effectively employs train as a symbol of opportunity knocking at you and conveying a message of 
seizing the opportunity is upto the person or else you would have to wait for the next opportunity. The train and the opening of the door have been effectively employed as a symbolic shot.

As mentioned in literature, the era of partition exhibited in movies still holds prominence and leaves a greater impact on the minds of people, yet on the other hand he documentaries leave us with a feeling of nostalgia in our hearts for things that long gone and can only be cherished.

\section{CONCLUSION}

In the following paper we have tried to understand the impact of railways beyond the economical and historical domains. The novels and travelogues play a crucial role in helping us understand the social impact of the railways and the lives of the people dependent upon it. The Railways has also made its space in the visual media, especially when we look at movies, some of them have really changed we just look at the railways and have made us realise that the railway not only exposes us to cultural diversity, but is a part and parcel of our everyday life.

\section{LIMITATIONS}

Lack of literary sources talking about the cultural significance of Railways

Sources not elaborated so as to facilitate interpretations about the significance of Railways in Visual Media

No general overview. The perceptions of common public not reflected

\section{SUGGESTIONS}

Scope for exploration of the role of railways in public domain

Researching the significance of employing railways as a symbolic shot and its impact in the people

Inculcating the role of travelogues in understanding railways

\section{REFERENCES}

[1] Aguiar, M. (2007). Railway Space in Partition Literature. In I. J. Kerr, 27 Down - New Departures in Indian Railway Studies (pp. 39-67). New Delhi: Orient Blackswan.

[2] Corbett, J. (2016). Loyalty. In R. Bond, The Penguin Book of Indian Railway Stories (pp. 93-108). Gurgaon: Penguin Books India Pvt Ltd.

[3] Ghosh, B. (2009). Chai Chai. New Delhi: Tranquebar Press.
[4] Kerr, I. J. (2012). The Pioneering Decades, ca. 1853 to ca. 1870. In I. J. Kerr, Engines of Change - The Railroads that made India (pp. 1-16). New Delhi: Orient Blackswan.

[5] Kohli, D. (2016, October 6). Bollywood on Wheels: 10 Movies Starring the Indian Railways. Retrieved February 04, 2017, from National Geographic Traveller India: http://www.natgeotraveller.in/railway reel-10-movies-where-trains-are-the-stars/

[6] Menon, V., \& Mahajan, S. (2007). Indian Nationalism and Railways. In R. Srinivasan, M. Tiwari, \& S. Silas, Our Indian Railways - Themes in Indian Railways History (pp. 155-172). New Delhi: Cambridge University Press India Pvt. Ltd.

[7] Mishra, R. N. (2009). Indian Railways: From Raj to Swaraj. In R. N. Mishra, Indian Railways Turnaround: A study in Management (pp. 1-9). New Delhi: Jaico Publishing House.

[8] Morey, P. (2007). Tunnels and Bridges: Railways, Narrative and Power in two Nivels of India. In R. Srinivasan, M. Tiwari, \& S. Silas, Our Indian Railways - Themes in Indian Railways History (pp. 214-225). New Delhi: Cambridge University Press India Pvt Ltd.

[9] Rajesh, M. (2012). Around India in 80 trains. New Delhi: Roli Books. 